\title{
GRANADA DES-GRANADA \\ Estudio de fundaciones hispano-árabes, aragonesas y castellanas como modelos de ciudad-ley en conflicto (ss. XI-XV)
}

\author{
Manuel Saga \\ Universidad de los Andes (Colombia). \\ Directoras de la investigación: Cristina Albornoz Rugeles, Claudia Mejía Ortiz. \\ E-mail: m.sanchez16@uniandes.edu.co
}

\section{RESUMEN}

Granada Des-Granada es un proyecto de investigación centrado en el estudio de las raíces legales y jurídicas del urbanismo ortogonal aragonés y castellano entre los siglos XI y XVI, en el contexto de su oposición al modelo de ciudad tradicional arabo-islámica durante la Reconquista Española. En este trabajo Granada constituye una categoría que reúne a las medinas andalusíes, mientras que Des-Granada es la denominación asignada al urbanismo foral hispano. Ambos modelos encarnan líneas fundacionales cuyo enfrentamiento es clave para la comprensión del modelo de urbanismo hispano consolidado en Iberoamérica.

En el presente documento se han analizado las raíces clásicas comunes a ambos modelos, mediante la metodología de análisis urbano propuesta Joseph Rykwert. Del mismo modo se han estudiado los modelos legales constituidos por los Fueros Aragoneses y la Sharía Islámica, así como su influencia sobre la morfología urbana de Granadas y Des-Granadas. Se exponen los resultados del trabajo de campo realizado en 2015 sobre de fundaciones aragonesas y castellanas, como hitos del urbanismo foral en la Península lbérica y antecedentes del urbanismo regido por las Leyes de Indias.

Palabras clave: Historia Urbana, Fundación de Ciudades, Medina Tradicional Árabo-islámica, Urbanismo Foral.

\section{ABSTRACT}

Granada Des-Granada (Grenade De-Grenaded) is a research project focused on legal and politic aspects of grid urbanism, as it was practiced by the kingdoms of Castilla and Aragón (XI - XVI cc), and its opposition to the traditional arab-muslim city model during the Spanish Reconquista. Granada has been used in this work as a category that covers all the Andalusian medinas. Des-Granada refers to Hispanic grid cities which were based on regional codes of laws called fueros. Both models represent opposed foundational concepts. Their shared origin is key for understanding the Hispanic urban model stablished in Ibero-America.

This document presents an analysis of both models as law-city constructs based in classic culture. A key aspect in this research are the law models of Aragon's Fueros and the Islamic Sharia, as well as their influence on the urban morphology of Granada and Des-Granada.The methodology proposed by the British architect Joseph Rykwert has been applied in this study. Two groups of Hispanic foundations have been object of field work during 2015, which results show their relevance as milestones of Hispanic grid urbanism evolution prior to 1492.

Key words: Urban History, City Foundation, Arab-muslim traditional city, law-driven urbanism. 


\section{INTRODUCCIÓN.}

"[...] para ir apoderándose de pueblo tras pueblo y fortaleza tras fortaleza y doblegar gradualmente todas sus defensas antes de intentar la toma de la capital de aquel reino: 'Sacaré una a una las semillas de esta granada', dijo el cauteloso Fernando."(Irving, 1831)

Granada Des-Granada es un proyecto de investigación ${ }^{1}$ centrado en el estudio de las raíces legales y jurídicas del urbanismo ortogonal aragonés y castellano entre los siglos $\mathrm{XI}$ y XVI, en el contexto de su oposición al modelo de medina islámica durante la Reconquista Española.

Granada, además del nombre de una ciudad y un reino, es en este trabajo una categoría que agrupa a las medinas tradicionales arabo-islámicas de Al-Andalus. Por otro lado, Des-Granada denomina a la ciudad en retícula propia del urbanismo foral hispano. Las Granadas eran ciudades antiguas, y complejas, levantadas sobre los restos de fundaciones romanas y fenicias, entre otras. Las Des-Granadas eran ciudades de avance, rápidas y ordenadas, fundadas para mostrar políticamente el poder cristianizante de Aragón y Castilla. Ambas responden a modelos urbanos herederos de la cultura clásica mediterránea, por lo que sus características diferenciadoras dan cuenta del proceso de definición del modelo de sociedad que representan y de las leyes que lo regulaban.

Granada Des-Granada parte de esta relación y utiliza las categorías fundacionales etruscas (Rykwert, 1976) para construir un panorama histórico basado en el cruce entre investigaciones centradas tanto en la ciudad hispano-árabe como en el urbanismo hispano. Este estado del arte se complementa con los resultados de trabajos de campo realizados sobre una selección de fundaciones en el Camino de Santiago y Andalucía occidental, junto a los casos específicos de Santa Fe y Santa Fe de Bogotá. Esta labor fue llevada a cabo durante los meses de agosto y septiembre de 2015 con la colaboración de los arquitectos Eva Mª Amate (España), Fabio Roldán (España) y Alfonso Arango (Colombia).

En este artículo se describen en primer lugar los seis elementos del rito fundacional etrusco, a partir de los cuales el arquitecto Joseph Rykwert propone analizar la ciudad ortogonal castellana (s. XIV). Frente a dicha propuesta se desarrolla un estudio de la fundación tradicional arabo-islámica, clave para entender los puntos de coincidencia y enfrentamiento entre Granada y Des-Granada. A continuación, se expone de forma breve la evolución del urbanismo ortogonal hispano a través de casos aragoneses (ss. XI-XIV), castellanos (ss. XIII-XIV), y castellano-aragoneses (ss. XV-XVI). ${ }^{2}$

\section{EL RITUS ETRUSCUS - METODOLOGÍA DE ANÁLISIS.}

Joseph Rykwert (Polonia, 1926) utilizó la obra del historiador Fustel de Coulanges (1830-1889) como fundamento para construir una metodología de análisis urbano basado del rito fundacional etrusco o ritus etruscus. En "La idea de ciudad" (Rykwert, 1976) Rykwert resalta la importancia de los aspectos míticos y religiosos presentes en el rito fundacional utilizado por etruscos, griegos y romanos, y los utiliza como metodología de análisis aplicada a fundaciones asiáticas y subsaharianas. Fabio Restrepo reafirma la relevancia de esta conexión entre rito, mito y fundación, una relación que ha evolucionado en el tiempo pero que no ha dejado de estar presente en el modo en que el ser humano crea y habita sus ciudades:

"Los ritos de fundación de la ciudad reproducen sobre la tierra la imagen del cosmos y los vínculos entre los dioses y los mortales. Orientar y fundar se confunden en un mismo acto. La posterior des-ritualización de la fundación y la conversión del trazar en una técnica que ya no necesita de la construcción física de sus límites, determinará el control del territorio [...] garantizado por la ciencia y la matemática. La construcción de la ciudad finalmente estará regida por la escritura alfabética, la norma y la ley." (Restrepo, 2016)

Los elementos que componen el ritus etruscus son seis: Templum, Mundus, Cardus y Decumanus, Sulcus Primigenius, Portæ y Laberinto. Su orden es jerárquico. Responde tanto a la sucesión de rituales propios del rito como a un nivel creciente de complejidad en la forma urbana. Cada uno de estos elementos está cargado de significados trascendentes, rastreables en los mitos clásicos y en las obras de cronistas como Plutarco y Ovidio. Se ofrece aquí una breve revisión del rito con el propósito de describir su valor metodológico.

\footnotetext{
${ }^{1}$ Universidad de Los Andes, 2014-2016. Presentado en diciembre de 2015 como tesis de investigación para la consecución del título de Magister en Arquitectura. Sustentada en enero de 2016. Grado Cum Laude en marzo de 2016.

${ }^{2}$ Consultar estudio completo en (Sánchez García et al., 2016)
} 


\subsection{Templum.}

Según la descripción de Plutarco, lo primero que hizo Rómulo antes de fundar Roma fue tomar el papel de augur, responsable de interpretar los signos divinos hasta encontrar el momento ideal para la fundación. Nadie se arriesgaría a fundar la urbs a la ligera, en una fecha inadecuada o sin certeza de los signos favorables. Este primer rito de interpretación es conocido como inauguratio. Tras ello se llevaban a cabo otros tres actos, mediante los cuales el augur pronunciaba la norma y se manifestaba sobre la fundación de la ciudad determinando qué elementos debían tomarse como hitos fundacionales. (Rykwert, 1976).

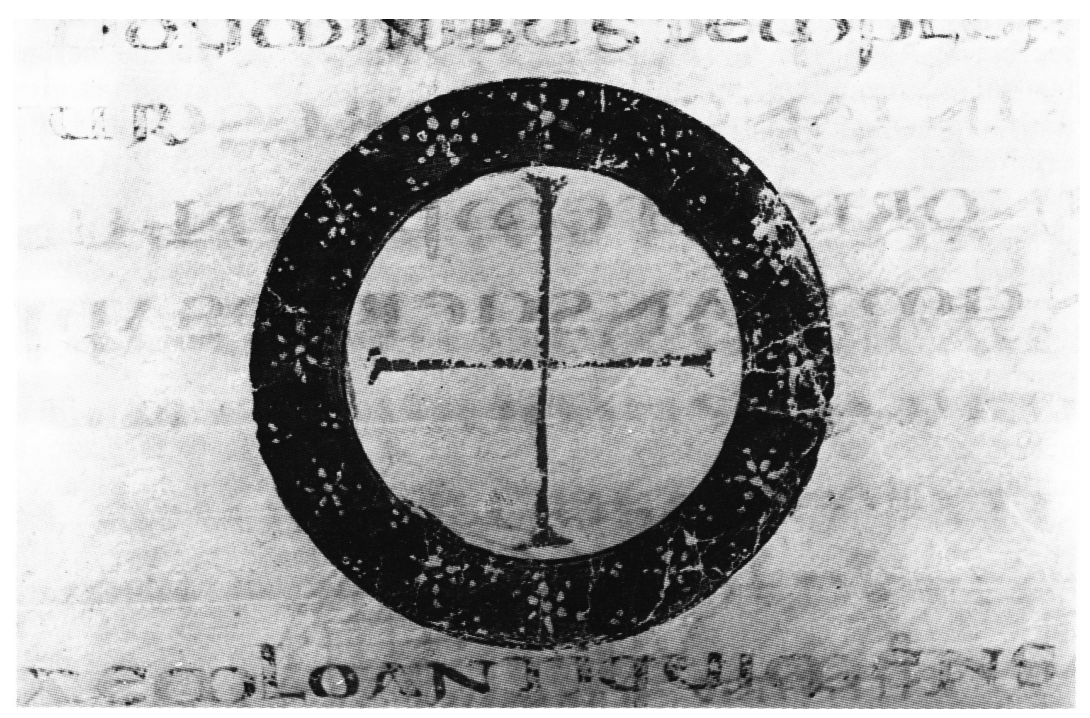

Gráfico 1: El templum del cielo. Miniatura que ilustra el texto de Higino Gromático, Constitutio Limitum el Codex Arcerianus. colección de escritos sobre agrimensura del siglo VI, Corpus Agrimensorum Veterum. Fuente: (Rykwert, 1976).

El augur buscaba identificar en la tierra los signos que los dioses hacían desde el cielo, y unirlos en una idea de ciudad. Las cuatro partes distinguidas en el diagrama que el augur dibujaba en la tierra, llamadas templa, se unían en un templum único [Gráfico 1]. El templum representaba así una serie de signos e interpretaciones comunes al pueblo que iba a fundar la ciudad. Para dar origen a la urbs era necesaria la interpretación sobre la tierra de los mitos y vínculos religiosos que unían a la civitas o grupo fundador. Se establecía así la relación entre lo humano y lo divino al tiempo que se separaba lo humano de lo no humano, es decir, el artificio de la naturaleza. El diagrama general de la ciudad, a menudo previo a ella, se convierte así en parte de central de su fundación. Constituye la idea de ciudad que precede a la ciudad misma.

\subsection{Cardus y Decumanus.}

Tras la finalización de los ritos augurales, o quizás de forma paralela a su desarrollo, entraban en escena los agrimensores. Es difícil imaginar el replanteo de una ciudad ortogonal sin alguna forma de técnica agrimensora, heredera de las primeras ordenaciones agrícolas en Babilonia y el Valle del Nilo. (Fustel de Coulanges, 1864). El agrimensor hacía uso del gnomon, dispositivo formado por una varilla de bronce situada sobre una placa de mármol en la cual estaba inscrito un círculo. Tras observar la sombra proyectada por la varilla y marcar los puntos en que cortaba el círculo antes y después del mediodía, se marcaba una línea entre ellos con una cuerda. Esta cuerda señalaba la orientación Este/Oeste, es decir el Decumanus, mientras que su perpendicular marcaba el norte y el sur, el Cardus. La orientación de la ciudad, indicada en el esquema general del templum, se constituía así la tierra a través de estas dos vías principales.

\subsection{Mundus.}

El mundus es el pequeño agujero que, según Plutarco, Rómulo horadó en la tierra en el momento de fundar Roma. Dentro de esta hendidura depositó un puñado de tierra de su lugar de nacimiento, práctica que repitieron tras él sus compañeros. Según Coulanges este ritual creaba una tumba ancestral compartida, un lugar en el que reposaban al mismo tiempo los dioses de todos sus fundadores sin importar la procedencia de cada uno de ellos: "También esta es la tierra de mis padres, terra patrum, patria; esta es mi patria, pues aquí están los manes de mi familia." (Fustel de Coulanges, 1864). Sobre el mundus se colocaba un altar 
ardiente, un hogar donde depositar ofrendas a los manes y otras divinidades. El mundus es el centro de la ciudad, su conexión con los antepasados, con los ritos, los mitos y la ley. Su ombligo.

\subsection{Sulcus primigenius.}

El cuarto elemento del ritus etruscus es el surco que marca el límite de la urbs. En Roma, Rómulo utilizó un arado de bronce para marcar esta frontera, la cual era inviolable pues pertenecía a los dioses, no a los hombres. Saltar el surco conllevaba la pena de muerte. El arado era símbolo de fertilidad ya desde el Neolítico, significado que llegó a la época clásica. Por otro lado, el bronce estaba dedicado al culto a Júpiter y los ritos arcaicos. El arado era tirado por un toro y una becerra, ambos blancos, situándose el macho en la parte externa de la urbs. Eran ritos con una gran carga sexual y de llamada a la fecundidad, con antecedentes que pueden rastrearse a lo largo de Oriente Medio y Asia (Rykwert, 1976).

Este ritual, conocido como sulcus primigenius, representaba la separación entre lo humano y lo divino. Dicho límite podía ser des-arado. Al igual que el surco tenía la capacidad de fundar la urbs, su contrario tenía el poder de destruir y de "des-fundar", así que el sulcus primigenius debía ser protegido mediante festividades y procesiones periódicas. Su relación con la ciudad era vital: si el mundus indicaba el lugar donde comenzaba la urbs el surcus primigenius marcaba su final. Se trata de un límite no necesariamente construido, no necesariamente levantado, que pertenece antes a los acuerdos religiosos, sociales y legales que al mundo de las fortificaciones y las empalizadas.

\subsection{Portæ.}

En ciertos momentos, tres según el rito etrusco, el arado se levantaba dejando sin marcar una parte del sulcus primigenius. Estos puntos serían las puertas de la ciudad, los únicos lugares por los que era posible acceder a la urbs sin violentar la alianza entre cielo y tierra que representaba su perímetro. Coulanges explica que las puertas se denominan como portæ, derivado del verbo latino portāre, levantar. La persona que la cruzaba era alguien que se adhería al pacto entre dioses y hombres que constituía la civitas, y al que la urbs había dado forma.

Todo punto de entrada posee además un protocolo asociado. Tanto el caballero al descubrir su rostro como el comerciante al declarar su mercancía cumplían el requisito de acceso a la ciudad, mostrando su acuerdo con la legalidad vigente. Aún hoy en día una persona sólo tiene permitido cruzar un número limitado de puertas, y cuando lo hace cumple ciertos rituales específicos: recitar una oración, tocar el timbre, recordar el santo y seña, "cariño soy yo".

\subsection{Laberinto}

Esta figura hace referencia a la trama interna de una fundación y a las características singulares que la diferencian de otras ciudades [Gráfico 2]. Para acceder al laberinto era necesario atravesar una puerta que a menudo se encontraba custodiada por un animal mitológico, como en la historia de Edipo y la Esfinge. El candidato a superar el laberinto debía pasar una prueba de sabiduría similar a un rito de iniciación. Esta podía consistir en responder una adivinanza, pronunciar una palabra clave o -más interesante- dibujar el laberinto para así demostrar que se conoce su trazado. El aspirante debía conocer la estructura de la urbs a la que pretendía acceder para responder al ritual de su puerta sagrada. El que desconociera su trama era seguramente un extraño, ajeno a la civitas. (Rykwert, 1976).

La representación del laberinto poseía una marcada similitud con la estructura de una ciudad ideal. Su proporción era a menudo cuadrada y poseía tanto un límite como una serie de puertas orientadas en las cuatro direcciones cardinales. Su centro aparecía marcado como un espacio vacío o un callejón sin salida. Contiene todos los elementos del ritus etruscus: templum, mundus, cardus y decumanus, límite y puerta, cinco prácticas a las que el laberinto añade una trama interior, una estructura compleja y diferente en cada ocasión. De este modo el laberinto representa el carácter propio de cada fundación, es decir, las peculiaridades de cada urbs. Ciudad y laberinto se confundían en una misma cosa: un conjunto de prácticas fundacionales comunes que adquirían una disposición única en cada ocasión. 


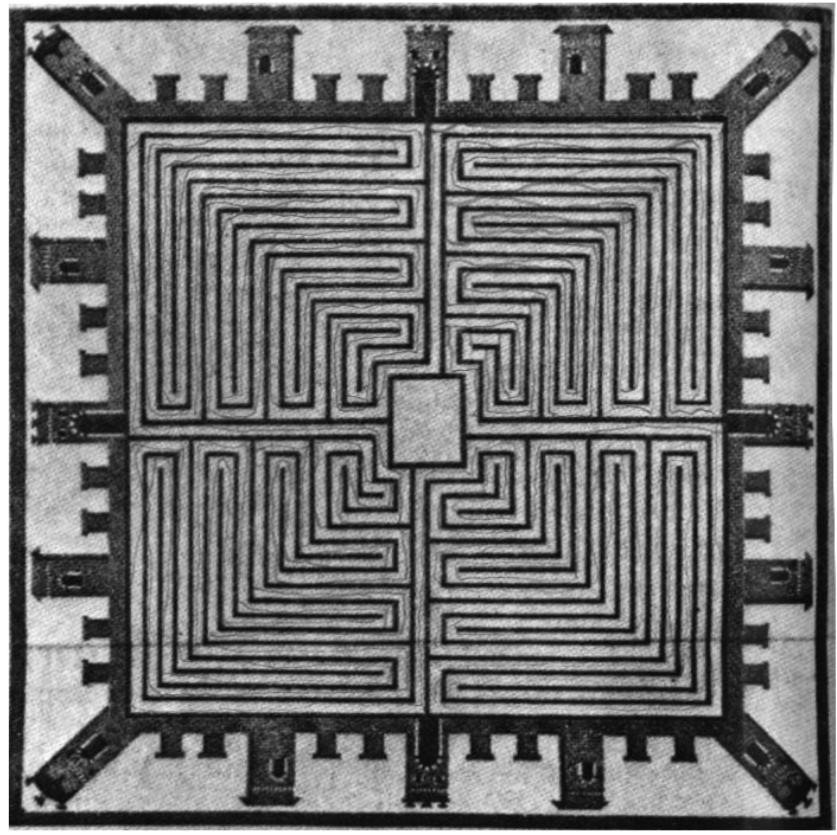

Gráfico 2: Mosaico romano de finales de la República, mostrando un laberinto fortificado. Fuente: (Rykwert, 1976).

\subsection{El Ritus Etruscus como herramienta metodológica}

Una vez definidos estos seis elementos -templum, mundus, cardus y decumanus, sulcus primigenius, portæ, y laberinto- Rykwert propone una serie de casos paralelos, rituales urbanos alejados del Mediterráneo que presentan coincidencias con las prácticas etruscas [Gráfico 3]. Sobre estos ejemplos se ponen a prueba el ritus etruscus como un conjunto de categorías de análisis, proponiendo una metodología para el estudio de las fundaciones urbanas (Rykwert, 1976).
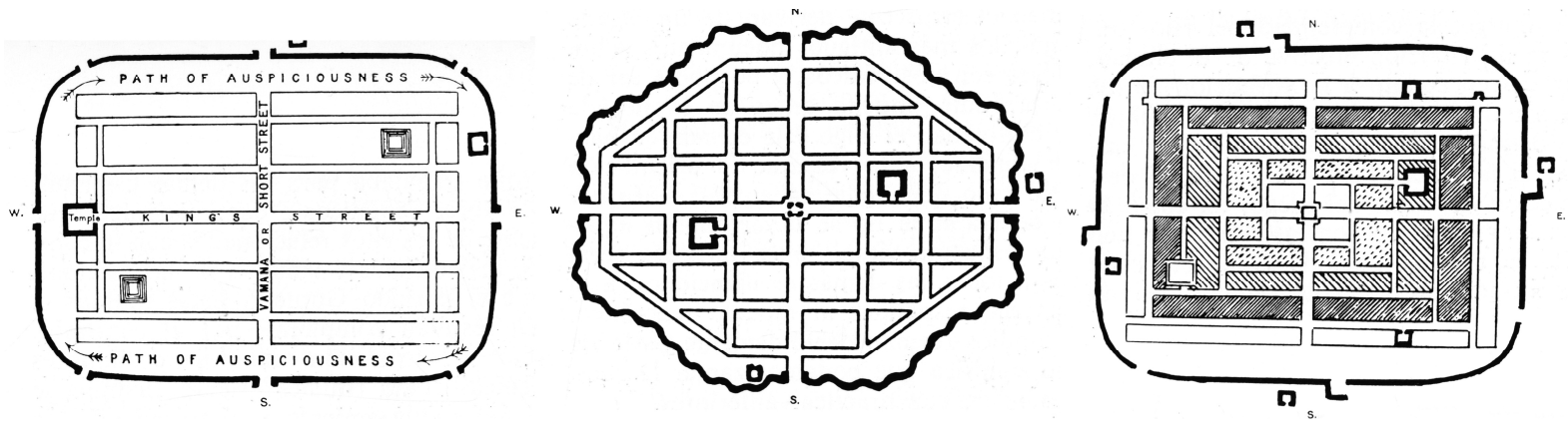

Gráfico 3: Tres de los ocho planos prototípicos de aldea especificados por el Manasara Silpasastra. Fuente: (Rykwert, 1976).

Las coincidencias entre estos distintos rituales y esquemas cósmicos no están asociadas necesariamente a una transmisión cultural directa. La propia naturaleza humana, deseosa de dar orden y sentido al mundo que la rodea, representa una conexión más fuerte que el mestizaje o la transculturación a través de rutas comerciales y de conquista (Rykwert, 1976). Rykwert propuso aplicar su metodología a otros casos entre los que se sugiere el urbanismo ortogonal hispano:

"Los príncipes cristianos españoles fundaron un considerable número de ciudades, de importancia diversa, que se atenían a una planta ortogonal, primero en el sur y más adelante, empezando por Briviesca, cerca de Burgos, también en el norte. Aquellas ciudades eran ejemplos señeros del poder y el orden que garantizaba el príncipe. La misma Briviesca era una fundación romana repoblada hacia el año 1208 y planificada 
de nuevo en 1315. Fernando e Isabel siguieron la misma tradición y, con los primeros asentamientos del Nuevo Mundo, aquella política se amplió a vastos y aún desconocidos." (Rykwert, 1976)

Granada Des-Granada recoge este testigo para realizar un análisis de los modos de fundación hispanos y sus diferentes vertientes. A esta tarea añade el estudio de las estructuras fundacionales arabo-islámicas, cuya omisión en "La Idea de Ciudad" no está justificada por su autor. Si tal y como lo describe Rykwert el urbanismo ortogonal hispano demostraba el poder cristiano, merece la pena estudiar también los modelos aplicados por sus enemigos en Al-Ándalus. Una civitas como la andalusí, heredera del Califato Omeya de Damasco, debía poseer sus propias tradiciones fundacionales para la construcción de la urbs.

\section{GRANADA: LAS CATEGORÍAS FUNDACIONALES ETRUSCAS EN LOS RELATOS FUNDACIONA- LES ISLÁMICOS.}

La estructura urbana de las Granadas se deriva del modelo de medina arabo-islámica ${ }^{3}$ : compacta, amurallada, de calles estrechas y trazado irregular. Medina, la capital que da nombre a todas las ciudades del Islam, fue fundada por el Profeta Mohammed en el año 622 d.C., el año de la Héjira. ${ }^{4}$ En los textos sagrados del Islam se narra cómo el Profeta creó una nueva ciudad para unir a las tribus árabes como si de un nuevo Rómulo se tratase, fundando una urbs para la nueva civitas del Islam que él mismo predicó y por la cual había sido expulsado de La Meca. Estaba acompañada de los ritos apropiados para una fundación heroica:

"It is said that when the Prophet entered Medina, he did not want to decide by himself where to settle, and he therefore left it to his camel to decide, asking the ansar ${ }^{5}$ not to make the camel kneel down in any of the places but to leave her until she would stop and kneel down herself. Once she did, he decided that this would be his dwelling place (manzil). The area surrounding the site of the Prophet's dwelling and his mosque at that time seems to have been open or very slightly used. From then on, it seems that the area, designated as the main mosque, became the center of the city." (Shabbah, 876)

En este relato es posible identificar dos elementos semejantes al ritus etruscus. Primero la adivinación, el animal como medio para interpretar los signos divinos y designar el momento adecuado para inaugurar la ciudad-templum-. Segundo, el establecimiento de un centro ritual y político alrededor de la casa/mezquita del profeta -mundus-.

Otros relatos fundacionales islámicos hacen referencia al amsar, un tipo de ciudad militar de nueva planta utilizada para alojar los acuartelamientos y centros administrativos de las provincias árabes. Una de ellas es Al-Kufah (638), cuya fundación se describe en las cónicas del persa Al-Tarabi (923). Su relato hace referencia a las vías principales y especifica el orden en que fueron trazadas, su número, la categoría de cada una de ellas y el ancho de vía que les correspondía, de forma similar al trazado del cardus y el decumanus [Gráfico 4].

\footnotetext{
${ }^{3}$ Se ha utilizado esta palabra como traducción de arab-muslim y su equivalente en el francés, tal y como la utiliza el historiador Juan Calatrava Escobar en sus traducciones de Mohamed Métalsi y otros autores del mundo árabe. Ref. (Métalsi, 2007)

${ }^{4}$ Usualmente los trabajos de investigación centrados en el mundo árabe presentan las fechas según el calendario cristiano y el árabe al mismo tiempo. Por razones prácticas, en este documento se han expresado todas las fechas únicamente según calendario cristiano.

${ }^{5}$ Ansar: Grupo de seguidores del Profeta tras su éxodo desde la Meca.
} 


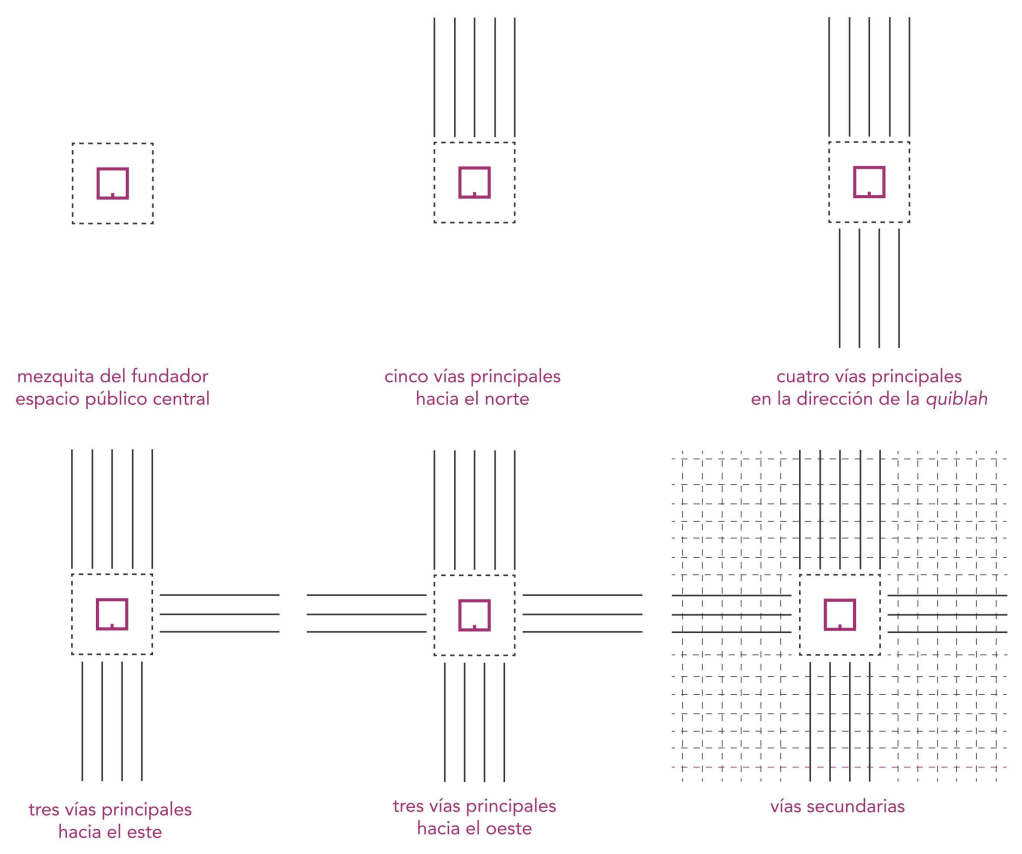

Gráfico 4: Esquema de la fundación de al-kufah. Fuente: elaboración propia.

Otro relato fundacional relevante es el de Baghdad, ciudad palatina fundada en el año 762 por el califa abasí Al-Mansur. El relato de su planeación ha llegado hasta nuestros días a través de Al-Khatib, historiador musulmán del siglo XI que describe numerosos detalles asimilables al ritus etruscus.

"[...] The circular city was divided into three zones. First, at the center, there was the al-rahbah, within this the palace of al-Mansur, the congregational mosque, and two other buildings were located. [...] In the second zone, the inner ring surrounding the rahbah, there were the residences of the younger sons of al-Mansur and his servants, and the different government agencies. In the third zone, the outer ring, there were the residences of the Caliph's army chiefs and his mawali."

"The city was walled and had four gates, each with an arcaded Street going all the way to the rahbah and thus dividing the city into four quadrants." (A. Al-hathloul, 1981).

Junto a estos relatos de nuevas fundaciones, se encuentran también medinas islámicas herederas de trazados clásicos. Damasco es un ejemplo de este grupo. Conquistada por los musulmanes en el año 635, en torno a 661 se estableció como capital del Califato Omeya. Su trama fundacional corresponde a Alejandro Magno y su conquista de Damasco en 323 a.C. [Gráfico 5]. Este caso no es excepcional: son numerosas las ciudades arabo-islámicas fundadas sobre restos de colonias griegas o romanas. Diversos investigadores hacen hincapié en este hecho como punto de conexión entre el mundo musulmán y las culturas clásicas (G. E. Von Grunebaum, 2010).

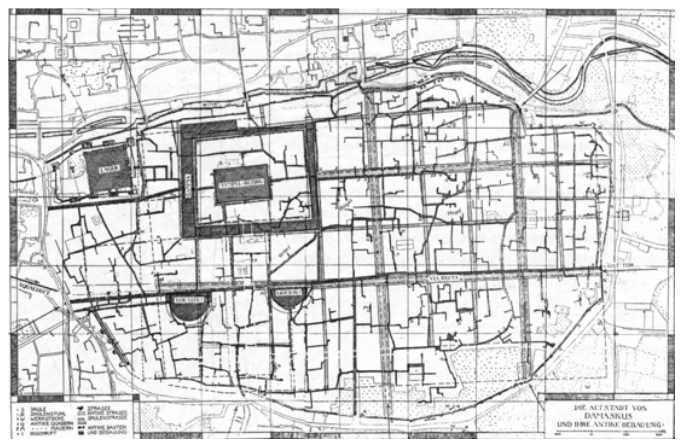

Gráfico 5: Plano de Damasco que muestra la grilla original del trazado helenístico-romano, sobrepuesto al tejido islámico posterior. Fuente: (Bianca, 2000). 
Esta misma circunstancia se da en muchas de las medinas andalusíes, fundadas sobre estructuras urbanas previas entre las que destacan las pertenecientes a la antigua Hispania romana (Torres Balbás, 1954). Córdoba, construida sobre los restos de la Colonia Patricia Corduba, (s. I a.C), es un ejemplo ilustrativo [Gráfico 6]. Autores como Basilio Pavón Maldonado hacen hincapié sobre la estructura de la medina de Córdoba y su relación con la ciudad clásica:

"El problema principal de las ciudades hispanomusulmanas radica en la aceptación o no de la continuidad o ruptura entre Roma y el Islam. [...] No es posible hablar de radicales rupturas; más bien nos encontramos con lentos procesos de transformación, perfectamente emblematizados en las mezquitas catedrales de los siglos VIII-X" (Pavón Maldonado, 1992).

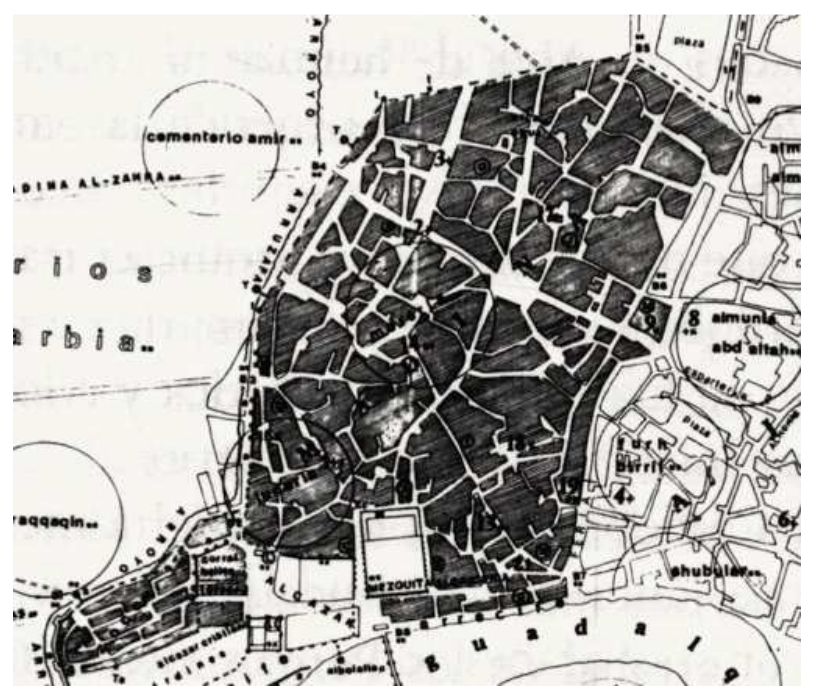

Gráfico 6: Medina de Córdoba. La medina amurallada está dividida en dos partes, en negro la sección fundacional árabe, en blanco las expansiones producidas tras la conquista cristiana. Fuente: (Pavón Maldonado, 1992).

Es posible identificar los elementos del ritus etruscus en la forma de Córdoba, aplicados del mismo modo que en las medinas de Oriente Medio. Esta medina presenta una estructura fundacional con una orientación definida -templum-, dos vías principales con una plaza en su intersección -cardus y decumanus-, y una mezquita mayor - mundus- situada junto a la puerta sur de origen romano (s. I a.C.). Sus murallas -sulcus primigenius- son similares a la de otras medinas amuralladas del sur de España, con puertas -portæ- fortificadas de entrada en recodo. Su trama -laberinto- es análoga a la de Damasco y Alepo, con agrupaciones de vivienda organizadas según los preceptos de la Sharía.

Los ejemplos de Medina, Al-Kufah, Baghdad, Damasco y Córdoba ilustran la conexión entre el modelo fundacional árabo-islámico y las tradiciones clásicas. Se trata de un sistema de ciudades-ley, que se distancian del modelo clásico a partir de la Sharía y de su aplicación a la vida urbana mediante manuales específicamente diseñados (A. Al-hathloul, 1981) (Saga, 2015). Medinas reales cuya gloria se busca asemejar al centro espiritual del Islam, ciudad divina. Si la Granada simbolizaba tal poder político y religioso, una DesGranada digna de oponérsele debía enviar un mensaje igual de poderoso.

\section{DES-GRANADA: ANÁLISIS DE CATEGORÍAS FUNDACIONALES ETRUSCAS EN LA CIUDAD FO- RAL ARAGONESA (SS. XI-XIV).}

Des-Granada se concibió como la construcción en la tierra de una ciudad utópica de origen divino, la materialización del "orden" de las leyes cristianas contrario al "desorden" de Al-Ándalus. En palabras de Vicente Bielza de Ory:

"El que en el ámbito pirenaico-aragonés se gestara un urbanismo regular a partir de los últimos decenios del siglo XI se debió a una concurrencia de factores que no se daba entonces en otros territorios [...]. En el creciente reino aragonés la reconquista obligó a una labor repobladora para lo que no había una burguesía en el territorio, que hubo de atraerse del exterior mediante fueros o privilegios, otorgados por unos reyes que podían disponer de suelo urbanizable para planificar de una vez y bajo el espíritu romanizante, introdu- 
cido a través de la Ruta Jacobea por la red de monasterios que tenía aquí una tierra de cruzada, especialmente apta para su realización." (Bielza de Ory, 2003).

Bielza de Ory ubica el origen del urbanismo ortogonal hispano en el Reino de Aragón durante la última década del siglo XI. En estos años se produjo la refundación de Jaca (1076) y Estella (1077) bajo leyes particulares e importantes movimientos políticos y religiosos. Es posible rastrear su influencia en multitud de fundaciones posteriores, tanto en la Península Ibérica como el Archipiélago Canario y América Latina. Entre los casos peninsulares se diferencian cuatro subconjuntos de fundaciones [Gráfico 5]

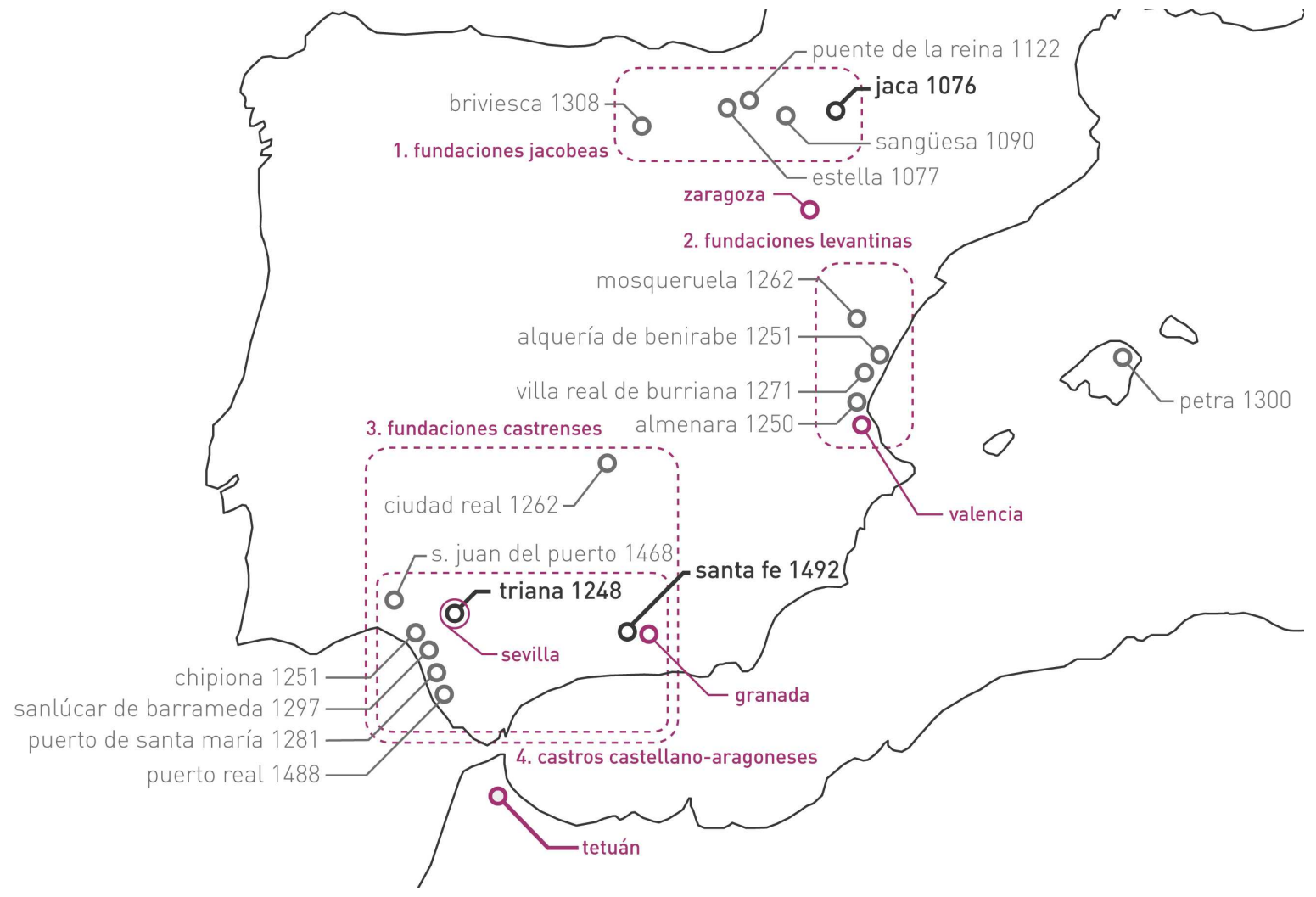

Gráfico 5: Grupos de fundaciones ortogonales hispanas en la Península lbérica, junto a su fecha de fundación. En rosado se señalan las principales medinas andalusíes en el territorio asociado a cada grupo fundacional. Fuente: elaboración propia.

Durante el desarrollo de Granada Des-Granada se realizaron trabajos de campo sobre fundaciones pertenecientes a los grupos 1, 3 y 4, junto al caso particular de Santa Fe de Bogotá en Colombia. Durante las visitas a estas ciudades se realizaron recorridos guiados por la identificación en la trama urbana de los elementos del ritus etruscus, enunciados por Joseph Rykwert. Estos elementos fueron levantados mediante dibujo in situ, aplicando la técnica desarrollada por Saleh Ali al-Hathloul para el registro de formas urbanas relacionadas con figuras legales (A. Al-hathloul, 1981). La combinación de estas dos metodologías ha permitido acometer el análisis de los espacios de representación política de estas fundaciones nacidas de la ley foral aragonesa. Su evolución fue paralela al crecimiento de los reinos de Aragón y Castilla, madurando a medida que el modelo de la Des-Granada apuntalaba el avance cristiano a través de la Península lbérica. [Gráfico 6]. 

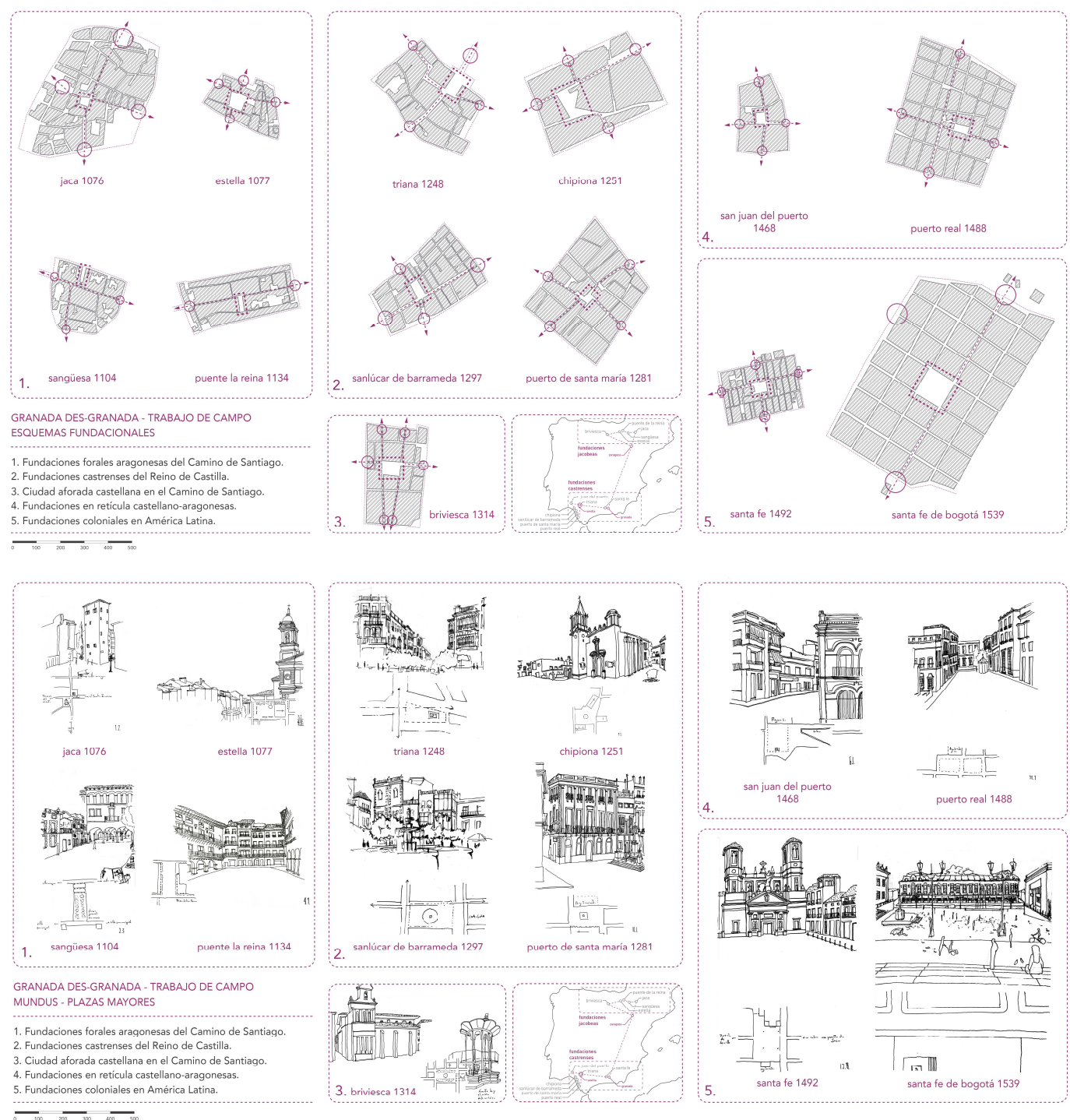
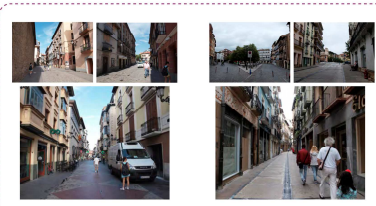

jaca 1076
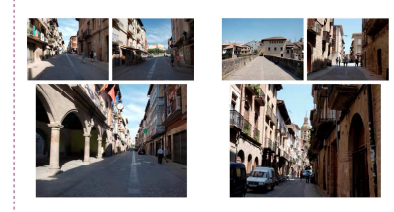

1. sangüesa 1104

puente la reina 1134

GRANADA DES-GRANADA - TRABAJO DE CAMPO CARDUS Y DECUMANUS - VIAS PRINCIPALES

1. Fundaciones forales aragonesas del Camino de Santiago. 2. Fundaciones castrenses del Reino de Castilla.
3. Ciudad aforada castellana en el Camino de Santiago 3. Ciudad aforada castellana en el Camino de Santiago
4. Fundaciones en reticula castellano-aragonesas. 5. Fundaciones coloniales en Amsira Latra

\section{$\tau_{0100}=-$}

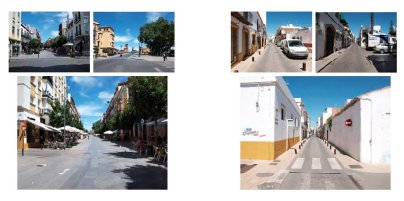

trianna 1248
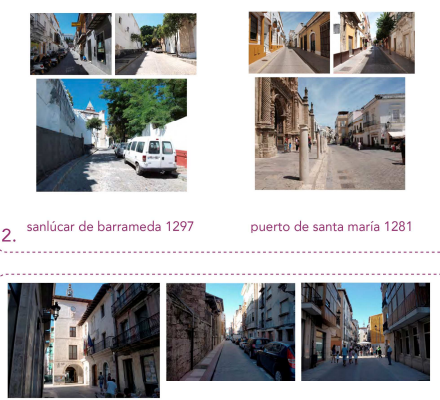
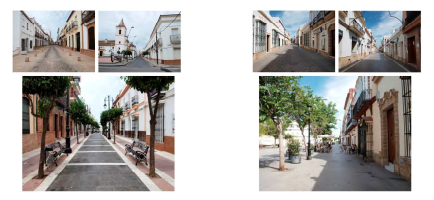

puerto real 1488

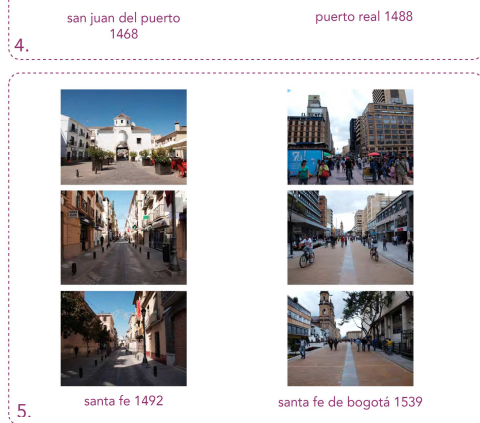

Gráfico 6: Síntesis de los resultados obtenidos mediante trabajo de campo en agosto y septiembre de 2015. Fuente: elaboración propia. 


\subsection{Grupo 1: fundaciones jacobeas. El fuero de Jaca, relación con la ciudad divina y medidas legales para la atracción de nueva población.}

Bielza de Ory señala la ampliación de la ciudad de Jaca en 1076 como primer antecedente de la recuperación del urbanismo ortogonal en Europa tras la caída del Imperio Romano de Occidente. Esta operación se enmarca en el contexto del Camino de Santiago o Ruta Jacobea, un sistema de senderos que conecta los principales núcleos urbanos de Europa con la catedral de Santiago de Compostela. La red territorial conformada por el Camino adquirió una gran importancia a partir del siglo IX como eje de expansión de los reinos cristianos y frente de defensa contra el avance árabe. Las ciudades fundadas en este contexto adquirían la forma de burgos fortificados llamados villes d'accession (Lavedan, 1952), que se estructuraban en torno al Camino como eje vertebrador (Passini, 1984). Este es el caso del castro antiguo de Jaca.

La refundación de Jaca fue una operación clave para el nacimiento del Reino de Aragón, título otorgado al antiguo Condado de Aragón en el momento en el que su rey Sancho Ramírez I se convirtió al cristianismo católico. Este gesto político significaba la alianza del nuevo reino con las monarquías católicas del resto de Europa, unidas por su cruzada común contra Al-Andalus. Una operación de este tipo precisaba de una construcción simbólica: un espacio físico -urbs- que delimitara el lugar representativo del nuevo pacto entre el rey y la divinidad -civitas-. El referente clave en este sentido es la Jerusalén Celestial-templum- [Gráfico 7] (Burckhardt, 1980) (Salcedo Salcedo, 1996) (Lucena Giraldo, 2006). En el Nuevo Testamento el apóstol San Juan la describe como una ciudad ortogonal, similar a la traza hipodámica que podía observar en la isla de Patmos. Por otro lado, en el Antiguo Testamento se expone la interpretación del modelo urbano mesopotámico, sacralizado por el pueblo judío. Ambos esquemas respondían a las categorías del ritus etruscus. Se trata de una única idea de ciudad, una sola ciudad divina conceptualizada de forma diferente en distintos momentos de la historia (Bielza de Ory, 2003).

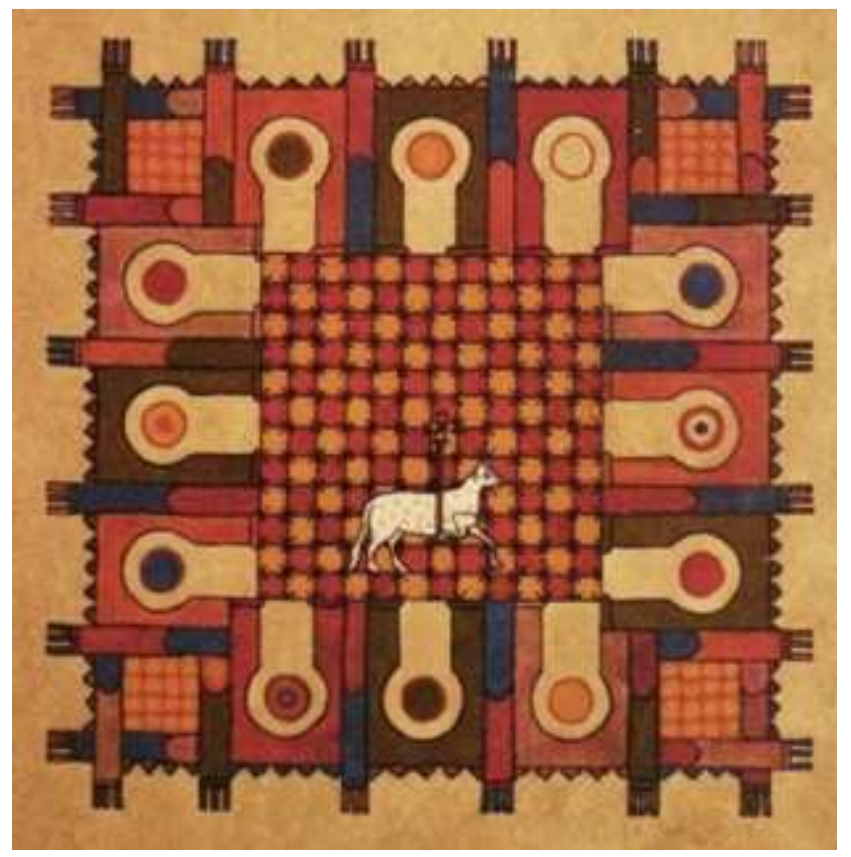

Gráfico 7: Modelo de Jerusalén Celestial del Beato de Liébana. Códice de Fernandi I, siglo XI. Fuente: (Burckhardt, 1980)

Otro referente de ciudad ortogonal para la fundación de Jaca es Cesaraugusta. la actual Zaragoza, nombrada en el año 14 a.C. en honor al emperador romano César Augusto. Durante el reinado de Sancho Ramírez esta ciudad pertenecía a la taifa andalusí de Zaragoza. Para los reinos cristianos del norte de España Zaragoza simbolizaba la conexión con sus antecedentes visigodos y la pasada gloria de Roma.

No obstante, en 1076 el Reino de Aragón carecía de capital. No poseía una ciudad representativa, por lo que sufría una situación de inferioridad frente a reinos enemigos y aliados. Sancho Ramírez precisaba de un mecanismo que le permitiera fundar una capital digna de la nación aragonesa recién convertida al catolicismo, y que al tiempo le permitiera atraer a un grupo de personas lo suficientemente poderosas para asegurar 
su prosperidad. Para ello emitió un fuero, es decir, una ley que se aplicaba únicamente al ámbito de Jaca y que concedía privilegios especiales a aquellos que se afincaran en ella. Entre las medidas del fuero se encuentran la protección de actividades agropecuarias y comerciales, la penalización de las pesas y medidas falsas, la regulación de las artesanías y el otorgamiento privilegios a los inmigrantes francos (cristianos) frente a los judíos o sarracenos (Bielza de Ory, 2003).

El Fuero de Jaca destacaba especialmente por la protección de la propiedad privada, ejemplificada en el lema "parcelas iguales para hombres iguales". La nueva ciudad del rey Sancho Ramírez poseía una serie de vías ortogonales -cardus y decumanus- que cruzaban dos ramales norte/sur del Camino de Santiago. Estas nuevas vías en sentido este-oeste se convirtieron en los ejes vertebradores de la ciudad. En el centro del ensanche -mundus- se ubicó el palacio real de la época. El conjunto se rodeó con una cerca -sulcus primigenius- y se establecieron seis accesos controlados -portæ: uno al norte, dos al sur, uno al oeste y dos al este [Gráfico 8]. Jaca se acercó así al ideal de ciudad divina existente en el imaginario de los pueblos cristianos. Una nueva urbs cristiana, católica y romana, que mostraban su identidad frente al andalusí. Esta era la herramienta utilizada por Sancho Ramírez para atraer nueva población a una situación de frontera dinámica, peligrosa e impredecible (Torres Balbás, Cervera, \& Bidagor, 1954).

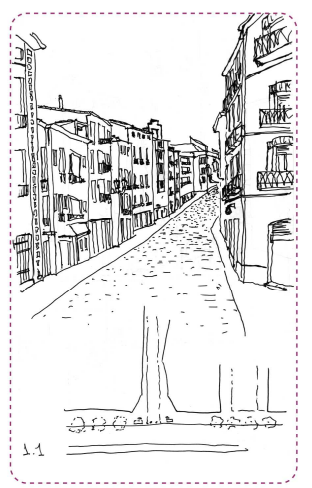

1.1. Portæ: entrada oeste

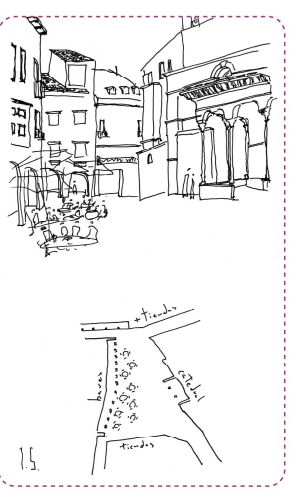

1.2. Plaza de la catedral
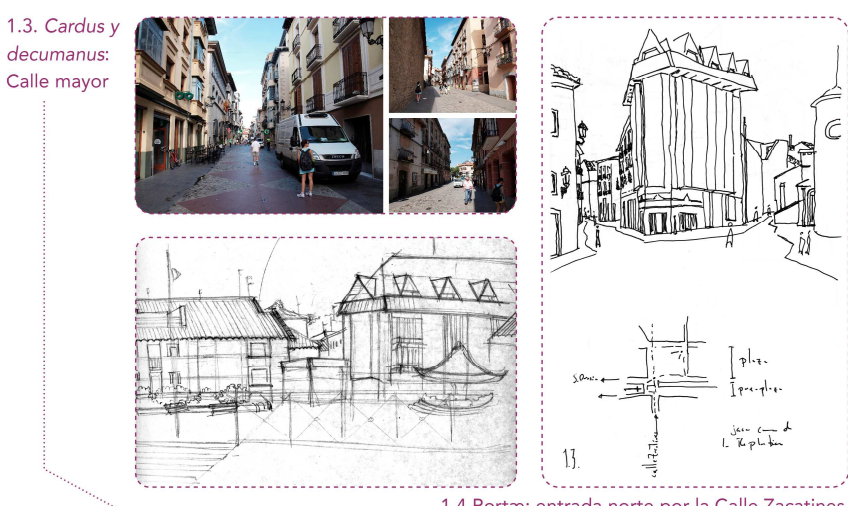
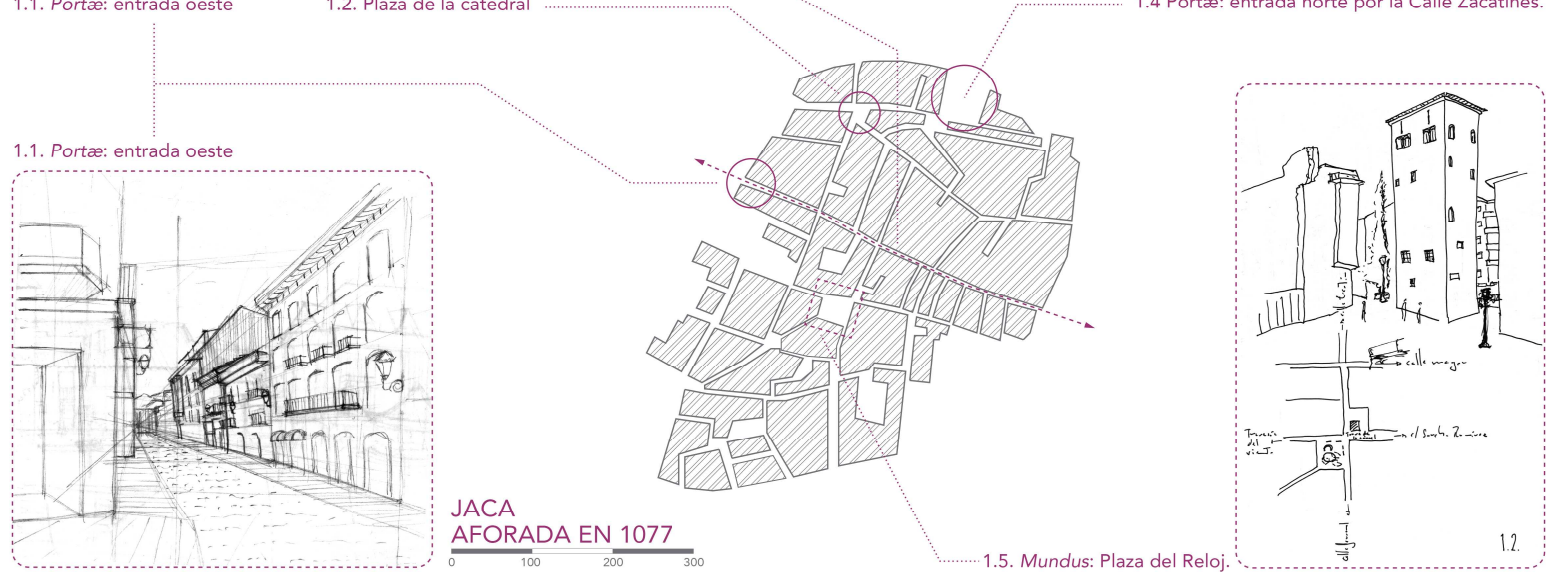

Gráfico 8: Resultados de trabajo de campo sobre la trama foral de Jaca.

Fuente: Elaboración propia.

El Fuero de Jaca obtuvo un gran éxito como modelo de ley urbana. En el 1077, tan sólo un año después, el propio Sancho Ramírez lo aplicó al burgo navarro de Lizarra, conocido a partir de ese momento como EsteIla. La ciudad experimentó un crecimiento similar al de Jaca, saltando el límite natural del río Ega y generando una nueva trama de calles ortogonales en cuyo centro se ubicó la Plaza de los Fueros, el edificio del cabildo y la Iglesia de San Juan. Estos dos hitos marcaron la tradición foral aragonesa, cuya difusión ha sido documentada gracias a la conservación de fueros locales herederos del modelo de Jaca (Bielza de Ory, 2003). 


\subsection{Grupo 2: fundaciones levantinas. Avance de Aragón contra Al-Ándalus y perfeccionamiento del urbanismo foral.}

El avance de la frontera con Al-Andalus durante el siglo XIII a lo largo del Levante Peninsular trajo consigo un nuevo tipo de fundación ortogonal. A diferencia de la tradición Jacobea, que otorgaba fueros a ciudades ya fundadas y las ampliaba o modificaba para que cumplieran las condiciones de la nueva ley, en la zona del Levante se realizaron fundaciones de nueva planta cercanas a núcleos andalusíes recién conquistados [Gráfico 9].

"Un rectángulo con cuatro cubos en los ángulos, cortado por dos calles perpendiculares, formando cruz, en cuyo encuentro se dispuso la plaza y en ésta la iglesia, casa del concejo, cárcel, etc., mientras en sus extremos se abrían puertas fortificadas. Las calles secundarias se trazaron paralelas a las del crucero. Estas villas levantinas son de más geométrica regularidad que las navarras [...]" (Torres Balbás et al., 1954).

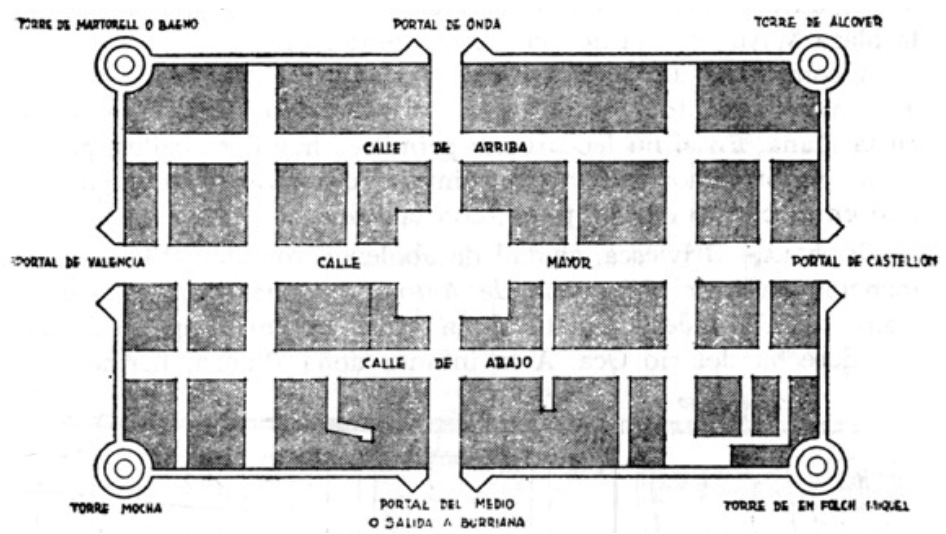

Gráfico 9: Abajo - Plano de Villareal de Burriana en el siglo XVI. La disposición según el ritus etruscus es clara. Fuente: (Torres Balbás et al., 1954).

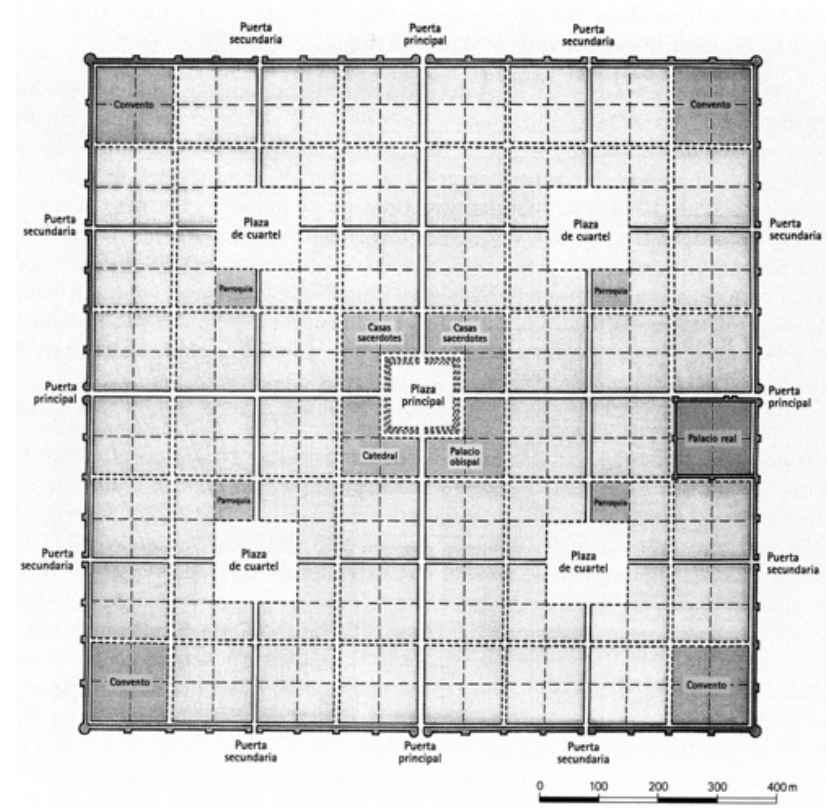

Gráfico 10: Modelo de ciudad teórica de Francesc de Eiximeniç, descrito en Lo Crestià (Lo cristiano), 1383. Fuente: (Bielza de Ory, 2003), basado en (Terán, 1989)

Esta etapa de avance militar y expansión de las jurisdicciones urbanas coincidió en el campo de la filosofía escolástica con el cambio a lo largo del siglo XIII desde las teorías neoplatónicas de San Agustín al pensamiento aristotélico de Santo Tomás de Aquino, transmitido a través de los andalusíes Averroes y Maimónides. Este cambio proponía la posibilidad construir el espacio de lo divino en la totalidad de la ciudad y no 
sólo en el templo, lo cual otorgó a la urbe un papel representativo del orden social y espiritual de la sociedad (Bielza de Ory, 2003). La renovación del pensamiento aristotélico no tardaría en generar diversas propuestas de ciudades ideales, siendo una de las más conocidas la descrita por el obispo aragonés Francesc de Eiximeniç en el siglo XIV [Gráfico 10]. La difusión de los fueros aragoneses alcanzó de este modo la categoría de tendencia filosófica, combinando la herencia clásica y la teología medieval en una idea de ciudad utópica:

"La obra humana preconcebida, planificada, puede ser la ciudad. El pensamiento que proyecta la forma que hay que darle a la materia -en este caso el lugar en el que se asienta la ciudad- puede universalizarse, puede acomodarse a unas reglas transmisibles en el tiempo y en el espacio." (Bielza de Ory, 2003).

\subsection{Grupo 3: Fundaciones castellanas en el sur de la Península Ibérica s. XIII.}

Las principales plazas fuertes castellanas eran de fundación antigua, muchas de ellas tomadas a los árabes como fueron los casos de León (conquistada en 856), Soria (1080), Madrid (1083) o Toledo (1085). También se encuentran fundaciones ortogonales en Castilla, pero estas no tuvieron un origen legal sino militar, campamentos castrenses sin fuero propio cuya trama se consolidó al serles concedidos cabildo y parroquia. Este es el caso de Triana, barrio de Sevilla creado a partir del campamento erigido por Fernando III para la conquista de Isbaliya en 1238 [Gráfico 11]. Triana posee una trama ortogonal definida, pero en el lugar donde debería encontrarse su plaza mayor -mundus- no existe un espacio público o edificio de relevancia política ni religiosa. Esto se explica porque Triana es un espacio anexo a la medina de Sevilla: no poseyó nunca instituciones propias.
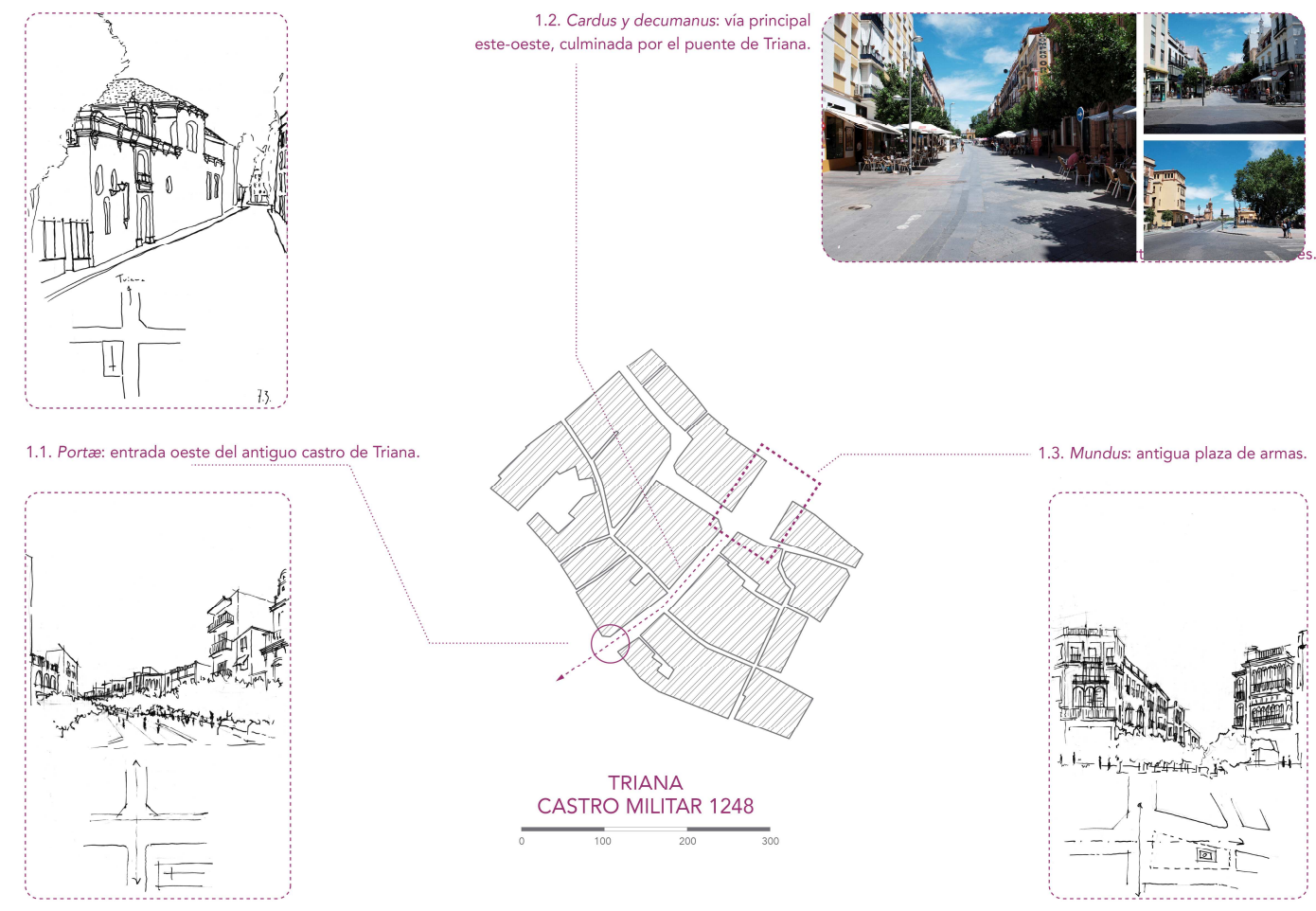

Gráfico 11: Resultados de trabajo de campo sobre el barrio de Triana, Sevilla.

Fuente: Elaboración propia.

La tradición de campamentos militares de Fernando III fue continuada por su hijo Alfonso X, el cual participó activamente en el asedio de Sevilla. Bajo su reinado se fundaron las ciudades de Chipiona (1251), Puerto de Santa María (1281) o la repoblación de Sanlúcar de Barrameda (1297) [Gráfico 12]. Todas estas ciudades fueron en su momento espacios de frontera en la campaña contra Al-Andalus, muy cercanas geográficamente a la batalla de Cádiz en 1262, la toma de Tarifa en 1292 o la batalla de Salado en 1340.

El urbanismo castellano del siglo XIII estaba pues relacionado con la situación de frontera y con la idea del castro romano como modelo de campamento militar. Su estructura podría leerse a partir del ritus etruscus 
pero carece de la característica más importante: no eran urbs. No constituían la identidad nacional. Esa responsabilidad reposaba en otras ciudades de origen antiguo como Toledo, las cuales sufrieron importantes modificaciones para responder a su papel como garantes del poder.

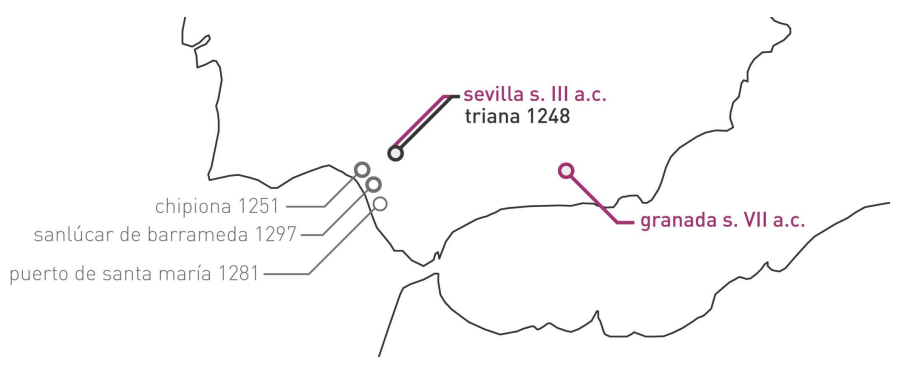

Gráfico 12: Ciudades ortogonales fundadas por Fernando III y Alfonso X (s. XIII d.C.) Fuente: elaboración propia.

Aunque estas fundaciones militares no poseyeran fueros propios, la labor legisladora de Alfonso $X$ constituyó un elemento determinante en la historia urbana del Reino de Castilla. Además del "Fuero Real" que recopilaba leyes históricas locales como la de Sepúlveda, entre 1256 y 1263 se redactó el "Código de las Siete Partidas", un cuerpo legislativo supletorio inspirado en el derecho romano que, entre otros temas, controlaba diversos aspectos del ordenamiento territorial (Brewer-Carías, 2006). Su papel será clave más adelante.

\subsection{Caso singular: Briviesca, la "bien trazada" 1314.}

Briviesca es una de las ciudades castellanas en retícula más reconocidas en la literatura consultada [Gráfico 13]. Refundada en 1314, se le otorgó un fuero propio en el año 1313 por la infanta Doña Blanca, hija de Alfonso de Portugal (Torres Balbás et al., 1954). Briviesca es una ciudad Jacobea, conectada al Camino de Santiago en el área de Burgos. Su fundación fue contemporánea al momento de mayor desarrollo del urbanismo ortogonal aragonés.
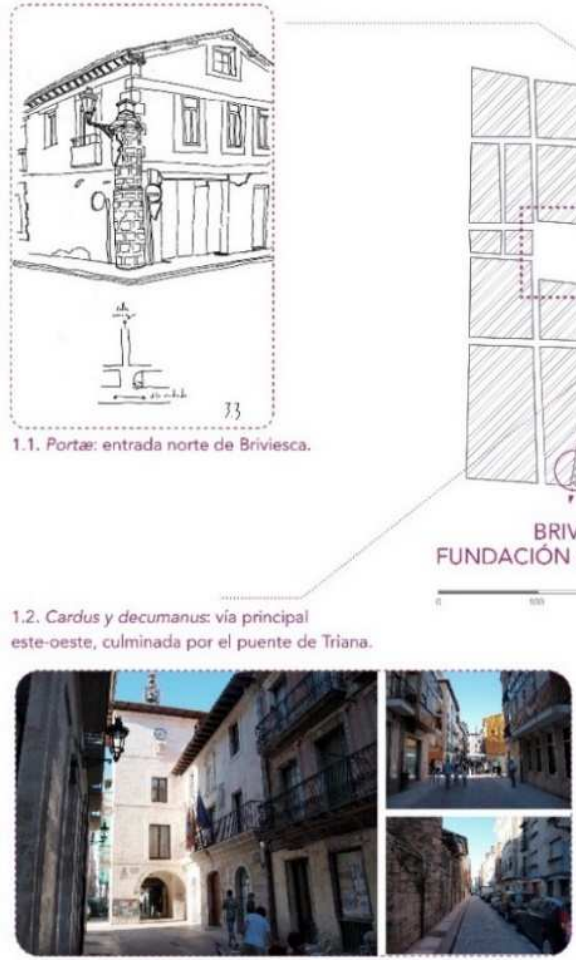
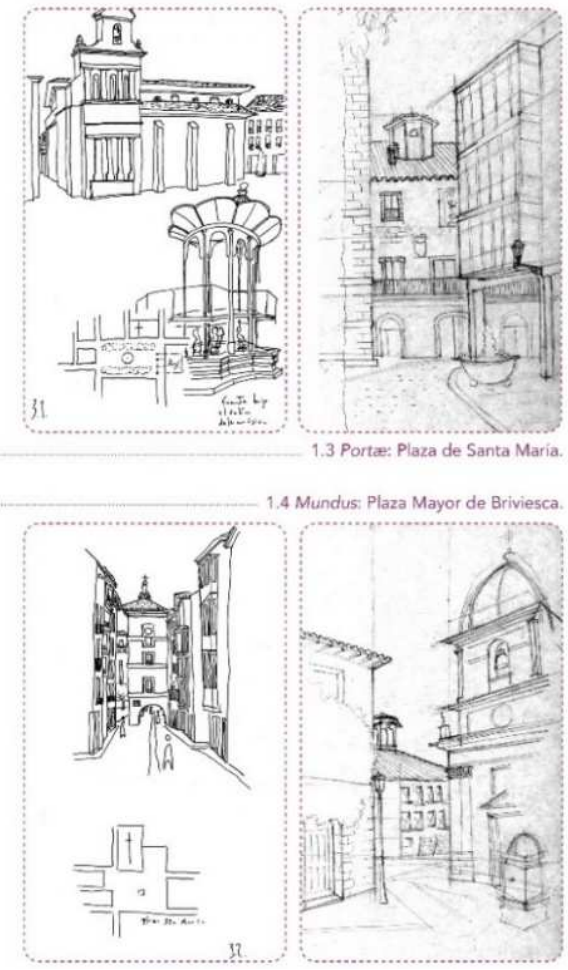

Gráfico 13: Resultados de trabajo de campo sobre Briviesca. Fuente: Elaboración propia. 
Su estructura corresponde a una ciudad ideal de nueva planta, a imagen de la Jerusalén Celestial templum-. En su centro geométrico se encuentra la plaza mayor -mundus-, donde se ubican la iglesia de San Martín y la Casa Palacio de los Soto, sede del cabildo. Sus vías principales -cardus y decumanusestán trazadas en dirección norte-sur y bordean la Plaza Mayor. El perímetro de la ciudad estaba amurallado -sulcus primigenius-, con puertas en los puntos de encuentro con las vías principales y secundarias portæ-. Las manzanas son de proporción sensiblemente cuadrada. Esta estructura le ha valido a la ciudad el apelativo de "la bien trazada" -laberinto- [Gráfico 14].

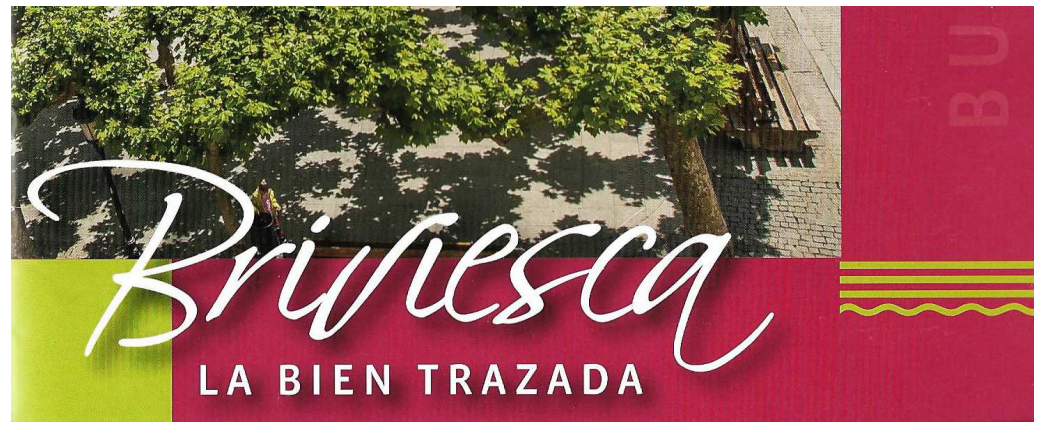

Gráfico 14: Recorte de folleto de información turística de Briviesca.

Fuente: Ayuntamiento de Briviesca.

Las características formales de Briviesca, junto a la concesión de un fuero propio, la convierten en un experimento urbano que unía el urbanismo castrense castellano con las prácticas fundacionales aragonesas que en el siglo XIV d.C. tenían ya más de doscientos años de historia. Briviesca aparece como un hito que favoreció la unión entre prácticas urbanas castellanas y aragonesas aisladas entre sí hasta el momento.

\subsection{Grupo 4: ciudad ortogonal castellano-aragonesa durante el final de la Reconquista s. XV}

En 1238, tras la derrota del Imperio Almohade y la toma de Sevilla, el noble Mohamed-Ben-Nazar fundó el Reino de Granada. Su frontera conservaría una estabilidad relativa desde el siglo III hasta finales del siglo $\mathrm{XV}$. Durante ese periodo la práctica del urbanismo ortogonal experimentó una pausa, asociada con el freno del avance cristiano. Habría que esperar hasta el reinado de los Reyes Católicos para que se reactivara el proyecto de la Reconquista, y con él la fundación de ciudades ortogonales.

Las primeras fundaciones asociadas a este periodo se enmarcaron dentro del proyecto de repoblación de Andalucía occidental, que carecía de la densidad demográfica de otras regiones. Entre ellas se encuentran San Juan del Puerto (1468) en Huelva, o Puerto Real (1477) en Cádiz, ambas muy cercanas a las ciudades ortogonales fundadas por Alfonso X en el s. XIII [Gráfico 15]. Su trama responde al modelo castrense, con manzanas sensiblemente cuadradas -laberinto- y una plaza central -mundus- donde se encontraban la iglesia y el cabildo.

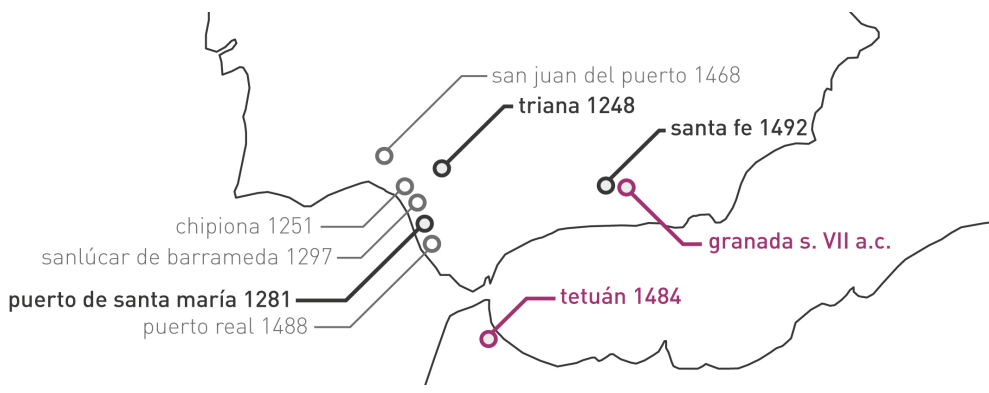

Gráfico 15: Ciudades ortogonales fundadas por Fernando III y Alfonso X (s. XIII d.C.). Fuente: elaboración propia.

La ciudad más relevante de este periodo fue Santa Fe, fundada a partir del campamento militar dedicado al asedio de Granada entre 1483 y 1492. Esta fundación no sólo poseía una estructura formal en retícula [Gráfico 16], sino que simbolizaba además el triunfo de los Reyes Católicos contra los reinos andalusíes, es 
decir, el fin de un conflicto que había durado más de ocho siglos. Santa Fe es la Des-Granada por antonomasia, la urbs que albergaba la civitas de los cristianos vencedores. Según el cronista Mármol Carvajal:

"Hicieron una ciudad cerrada de muros y de torres, con una honda cava, dejando dos calles principales en medio derechas, puestas en cruz, que van a dar a cuatro puertas, que responden a los cuatro vientos, quedando en medio una plaza de armas espaciosa y ancha, donde pueden juntarse la gente del ejército." (del Mármol Carvajal, 1600)

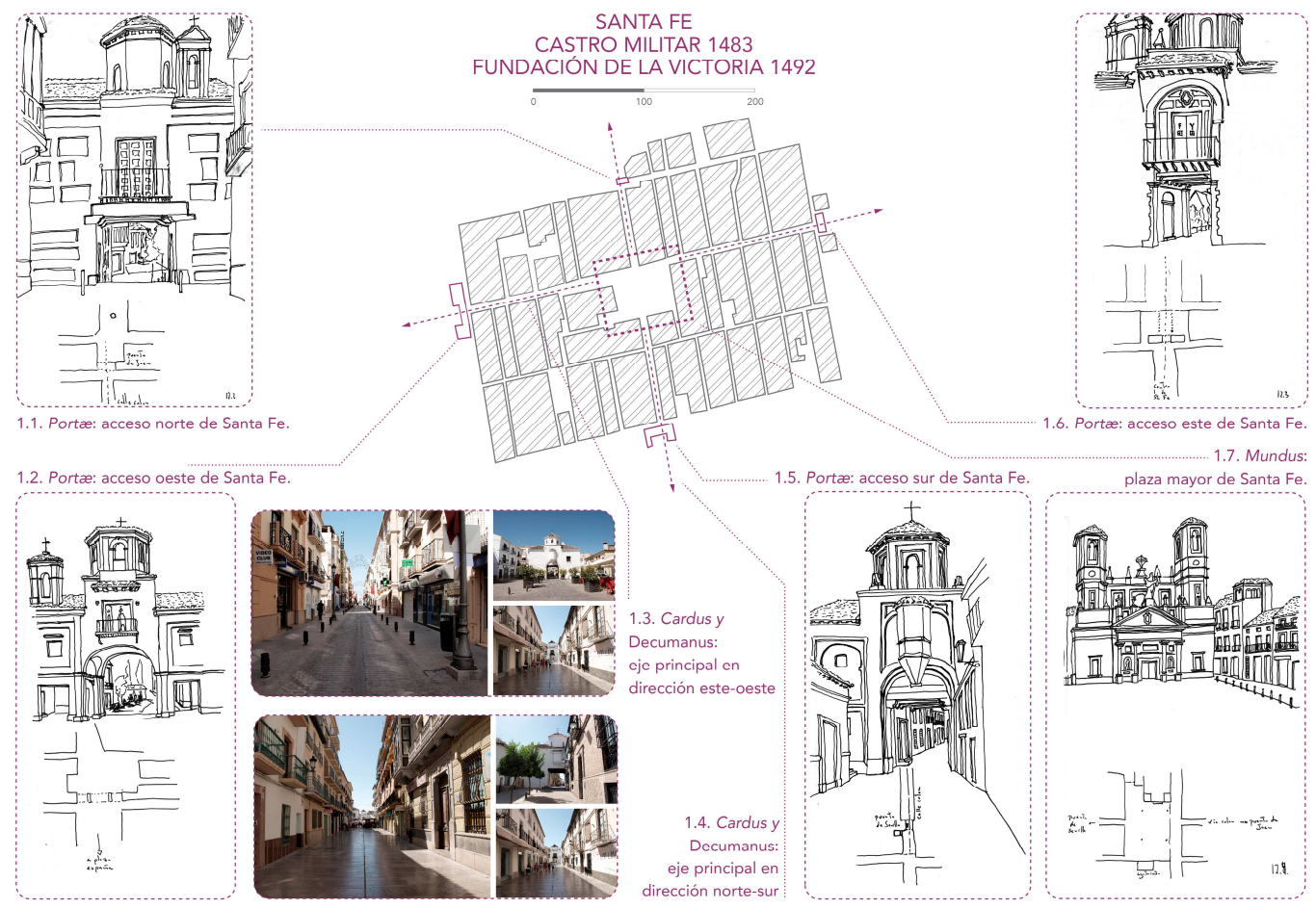

Gráfico 16: Resultados de trabajo de campo sobre Santa Fe. Fuente: Elaboración propia.

Lucio Marineo Sículo, cronista de Isabel y Fernando, afirmó que el plano de Santa Fe era una copia del de Briviesca (Marineo Siculo, 1539). Aunque las tramas urbanas de ambas ciudades son diferentes en muchos aspectos, esta aseveración demuestra la importancia de Briviesca como punto de articulación entre las diferentes tradiciones fundacionales. No hay que olvidar que, aunque Santa Fe pertenecía al Reino de Castilla, el comandante de sus huestes era Fernando, heredero del urbanismo foral aragonés. Esta confluencia convirtió a Santa Fe en una fundación muy influyente sobre empresas urbanas posteriores.

Tras el inicio de la conquista de América se siguieron fundando ciudades de trama ortogonal en la Península Ibérica, como es el caso de Villamartín (1502) o Paterna de Ribera (1563), pero no volvería a repetirse un ejemplo similar al de Santa Fe (Brewer-Carías, 2006). En este sentido, Santa Fe constituye un punto de conexión clave entre la evolución del urbanismo ortogonal hispano peninsular y sus futuros cambios en el continente americano.

\section{CONCLUSIONES: LA LEY COMO EJE VERTEBRADOR DEL URBANISMO CASTELLANO- ARAGONÉS Y SU EVOLUCIÓN EN AMÉRICA LATINA.}

El proyecto de conquista del territorio americano estuvo determinado desde un principio por la ley y el poblamiento. En el siglo XVI la adquisición de señorío sobre nuevas islas se basaba en cuatro sistemas descritos en el Código de las Siete Partidas de Alfonso X, de doscientos cincuenta años de antigüedad: mediante herencia, acuerdo entre sus súbditos, por casamiento o por otorgamiento papal (Ley 9, Título I, Partida II. Consultado en (Brewer-Carías, 2006). A estos cuatro se sumaba una excepción:

"Pocas vegadas acaece que se fagan yslas nuevamente en la mar. Pero si acaeciesse que se fiziese y alguna ysla de nuevo, suya dezimos que debe ser de aquel que la poblare primeramente; e aquel o aquellos 
que la poblaren, deben obedescer al Señor en cuyo señorio es aquel lugar do apareció tal ysla. Código de las Siete Partidas." Ley 29, Título XXVIII, Partida III. Consultado en (Brewer-Carías, 2006).

Esta figura legal fue la aplicada al caso americano, prevaleciendo sobre acuerdos posteriores como la bula Inter Coetera, emitida por el Papa Alejandro VI en 1493, o el Tratado de Tordesillas firmado por Castilla, Aragón y Portugal en 1494 (Brewer-Carías, 2006). El territorio americano no se conquistaba venciendo al enemigo ni clavando banderas, sino fundando ciudades. Nótese que una fundación de este tipo, vinculante a nivel jurídico, debía de cumplir una serie de protocolos estrictos para que no quedara resquicio de duda sobre el derecho adquirido con ella. El acto fundacional estaba descrito en las capitulaciones e instrucciones y se desarrollaba de manera uniforme, con la presencia de un escribano que levantaba acta. El conquistador y su hueste que ganaban la categoría de vecinos -civitas-. Toda fundación conllevaba el levantamiento en acta de la planta del centro poblado, señalando el lugar de la plaza, el cabildo y la iglesia -mundus-, la traza de las vías principales -cardus y decumanus-, y el repartimiento de los solares -laberinto- (BrewerCarías, 2006).

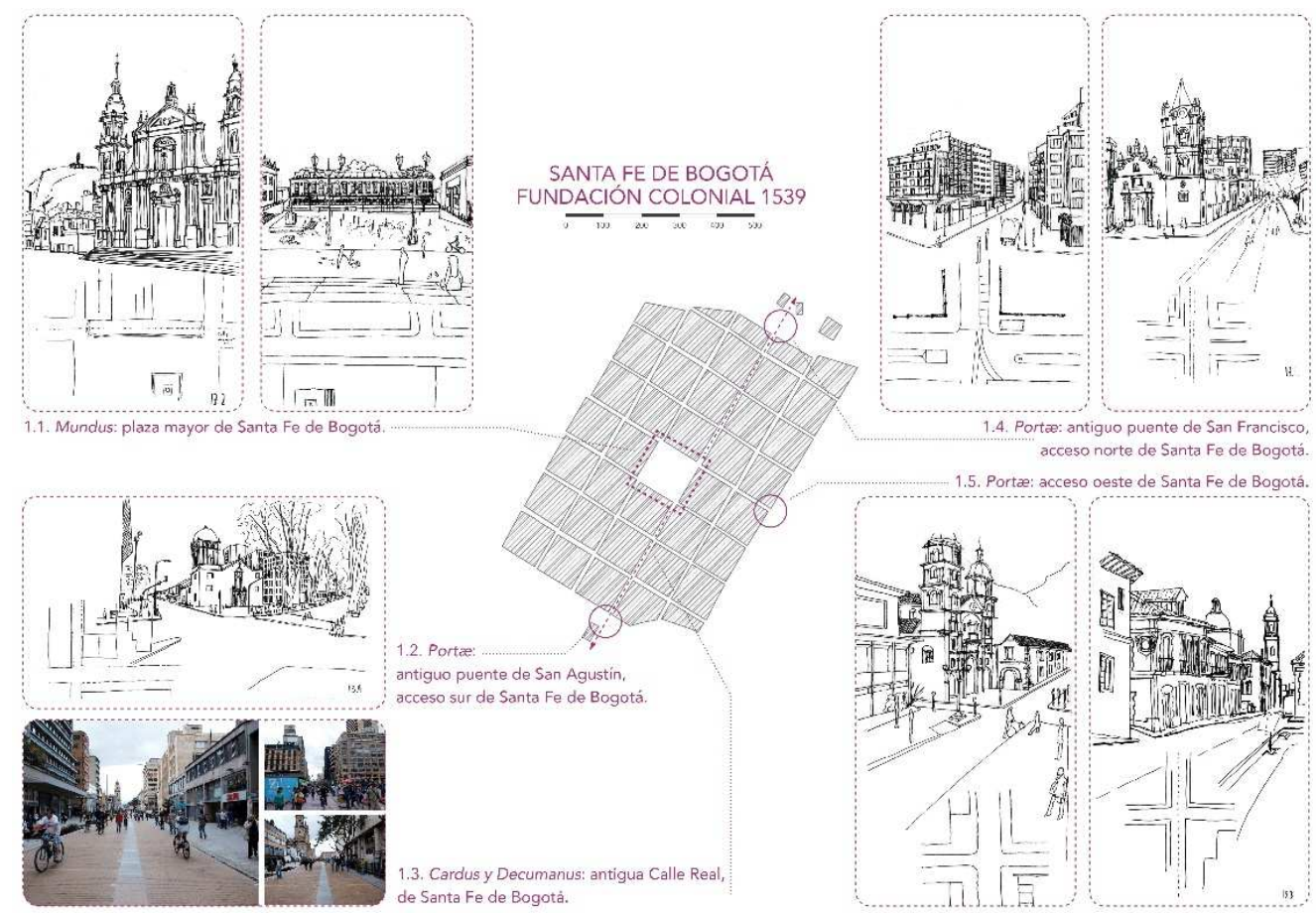

Gráfico 17: Resultados de trabajo de campo sobre Santa Fe de Bogotá.

Fuente: Elaboración propia.

Santa Fe de Bogotá, fundada por Gonzalo Jiménez de Quesada en 1538 junto a Nicolás de Féderman y Sebastián de Belalcázar, constituye un caso ejemplar de este proceso (Mejía Pavony, 2012). Su trazado y el proceso de su fundación corresponden tanto a las instrucciones dadas al adelantado Pedro Fernández de Lugo como a la tradición colonial establecida desde la refundación de Santo Domingo en 1503 [Gráfico 17].

Aunque este sistema de toma de posesión del territorio mediante fundaciones-ley poseía características nunca vistas hasta el momento, es clara la herencia recibida por los procesos fundacionales ya mencionados en el Camino de Santiago, el Levante y Andalucía. Podrían citarse otros ejemplos como la conquista de las Islas Baleares (s. XIV) o la de las Islas Canarias (s. XV d.C.), ambas ligadas al poblamiento. La conquista y colonización de américa constituye, por tanto, una parte de un proceso más amplio que arranca desde el mismo momento de la conquista árabe de la Península Ibérica en el año 711. En esta historia de largo recorrido es imprescindible contar con la relación entre el modelo de ley y ciudad árabo-islámico y el que más tarde practicarían los reinos cristianos bajo sus propias figuras legales y religiosas. Granada y DesGranada se presentan no como enemigos, sino como parientes cercanos y enemigos íntimos. Dos interpretaciones paralelas de una misma ley ancestral, sobre las cuales se presenta en este artículo un primer acercamiento. 


\section{BIBLIOGRAFIA}

A. Al-hathloul, S. (1981, febrero). Tradition, continuity and change in the physical environment : the ArabMuslim city (PHD). Massachusetts Institute of Technology. Recuperado a partir de http://dspace.mit.edu/handle/1721.1/46401

Bianca, S. (2000). Urban Form in the Arab World. London; New York, NY: Thames \& Hudson.

Bielza de Ory, V. (2003). El Fuero de Jaca, el Camino de Santiago y el urbanismo ortogonal. En El Fuero de Jaca. (Vols. 1-2, pp. 269-318). Zaragoza: Consejo Superior de Investigaciones Científicas, Instituto de Estudios Pirenaicos, Escuela de Estudios Medievales.

Brewer-Carías, A.-R. (2006). La ciudad ordenada. Caracas: Criteris Editorial.

Burckhardt, T. (1980). Símbolos. Palma de Mallorca: José J. de Olañeta. Recuperado a partir de http://www.valdemar.com.mx/sitio/pdf/SIMBOLOS\%20-\%20Burckhardt\%20Titus.pdf

del Mármol Carvajal, L. (1600). Historia de la rebelión y castigo de los moriscos del Reyno de Granada. Málaga.

Fustel de Coulanges, N. D. (1864). La ciudad antigua. Madrid: Editorial Plus Ultra.

G. E. Von Grunebaum. (2010). Islam: Essays in the Nature and Growth of a Cultural Tradition. Kessinger Publishing, LLC.

Irving, W. (1831). Crónicas moriscas: leyendas de la conquista de España. (L. Baéz Díaz, Trad.). Granada: Miguel Sánchez.

Lavedan, P. (1952). Histoire de l'urbanisme. Paris: Henri Laurens.

Lucena Giraldo, M. (2006). A los cuatro vientos : las ciudades de la América hispánica. Madrid: Fundación Carolina Centro de Estudios Hispánicos e Iberoamericanos : Marcial Pons Historia.

Marineo Siculo, L. (1539). De las cosas memorables de España / compuesta por Lucio Marineo Siculo, coronista de sus maiestades. Alcalá de Henares: Casa Juan de Brocar.

Mejía Pavony, G. R. (2012). La ciudad de los conquistadores: 1536-1604. Bogotá: Pontificia Universidad Javeriana.

Métalsi, M. (2007). Crisis en lo urbano en el mundo árabe. En La ciudad: Paraíso y conflicto (pp. 319-330). Madrid: Abada, Consejería de Obras Públicas y Transportes de la Junta de Andalucía,.

Passini, J. (1984). Villes medievales du chemin de Saint-Jacques-de- Compostelle (de Pampelune a Burgos) : villes de fondation et villes d'origine romaine. Paris: Editions Recherche sur les Civiliations.

Pavón Maldonado, B. (1992). Ciudades hispano-musulmanas. Madrid: Editorial Mapfre.

Restrepo, F. (2016). Cartografías de la identidad. Bogotá: Universidad de los Andes, Facultad de Arquitectura y Diseño, Departamento de Arquitectura ; Ediciones Uniandes ; Pontificia Universidad Javeriana, Facultad de Arquitectura y Diseño.

Rykwert, J. (1976). La idea de ciudad : antropología de la forma urbana en el mundo antiguo. Madrid: Hermann Blume.

Saga, M. (2015). La ciudad tradicional árabe: Un pariente no tan lejano (Parte 1) "La Ciudad Viva. Recuperado a partir de http://www.laciudadviva.org/blogs/?p=28228

Salcedo Salcedo, J. (1996). Urbanismo hispano-americano siglos XVI, XVII y XVIII: el modelo urbano aplicado a la América española, su génesis y su desarrollo teórico y práctico. Santafé de Bogotá: Pontificia Universidad Javeriana, Fac. de Arquitectura y Diseño : Centro Editorial Javeriano.

Sánchez García, M., Albornoz Rugeles, C., Castro Benavides, C., Salazar Ferro, C., Otero-Cleves, A. M., \& Lucena Giraldo, M. (2016). Granada des-granada : raíces legales de la forma urbana morisca e hispana. Uniandes, Bogotá : Recuperado a partir de WorldCat.org.

Shabbah, U. b. (876). Tarikh al-Madinah al-Munawwarah.

Terán, F. (1989). La ciudad hispanoamericana. El sueño de un orden. Madrid: Ministerio de Fomento.

Torres Balbás, L. (1954). La Edad Media. En Resumen histórico del urbanismo en España (1 ${ }^{\text {a }}$ Edición, p. 20 y ss.). Madrid: Instituto de Estudios de Administración Local.

Torres Balbás, L., Cervera, L., \& Bidagor, P. (1954). Resumen histórico del urbanismo en españa. Madrid: Instituto de Estudios de Administración Local. 